\title{
Immunohistochemical expression of heparin-binding protein 17/ fibroblast growth factor-binding protein-1 (HBp17/FGFBP-1) as an angiogenic factor in head and neck tumorigenesis
}

\author{
SHAHANA BEGUM ${ }^{1}$, YAN ZHANG ${ }^{1}$, TOMOAKI SHINTANI ${ }^{1}$, \\ SHIGEAKI TORATANI $^{1}$, J. DENRY SATO $^{2}$ and TETSUJI OKAMOTO ${ }^{1}$ \\ ${ }^{1}$ Department of Molecular Oral Medicine and Maxillofacial Surgery, Division of Frontier Medical Science, \\ Graduate School of Biomedical Sciences, Hiroshima University, Hiroshima 734-8553, Japan; \\ ${ }^{2}$ Mount Desert Island Biological Laboratory, Old Bar Harbor Road, Salisbury Cove, ME 04672, USA
}

Received October 10, 2006; Accepted November 14, 2006

\begin{abstract}
Heparin-binding protein 17/fibroblast growth factorbinding protein-1 (HBp17/FGFBP-1) is a secreted protein that releases immobilized fibroblast growth factor-2 (FGF-2) from the extracellular matrix and plays a critical role in FGF bioactivation. In the present study co-localization of FGF-2 and HBp17/FGFBP-1 was observed in oral tissues including normal mucosa, hyperplasia, dysplasia of different degrees and oral squamous cell carcinoma (OSCC). The expression score for HBp17/FGFBP-1, FGF-2 as well as vascular endothelial growth factor A (VEGF-A) became higher with the severity of epithelial dysplasia and was highest in severe dysplasia. The expression of HBp17/FGFBP-1, FGF-2 and VEGF-A showed significant association with microvessel density, but no correlation with TNM stages or OSCC recurrence interval. Our results demonstrated that $\mathrm{HBp} 17 /$ FGFBP-1, like VEGF-A and FGF-2, might also promote the induction of tumor angiogenesis. The strongest expression of angiogenic factors in severe dysplasia suggests a potential point for targeting novel anti-angiogenic therapeutic strategies.
\end{abstract}

Correspondence to: Dr Tetsuji Okamoto, Department of Molecular Oral Medicine and Maxillofacial Surgery, Division of Frontier Medical Science, Graduate School of Biomedical Sciences, Hiroshima University, Hiroshima 734-8553, Japan

E-mail: tetsuok@hiroshima-u.ac.jp

Abbreviations: HBp17, heparin-binding protein 17; FGF, fibroblast growth factor; FGFBP-1, fibroblast growth factor binding protein-1; VEGF-A, vascular endothelial growth factor A; OSCC, oral squamous cell carcinoma; MVD, microvessel density

Key words: premalignancy, angiogenesis, FGF-2, HBp17/ FGFBP-1, VEGF-A

\section{Introduction}

Neovascularization is a critical event in tumor progression such that tumor growth beyond a few millimeters requires an adequate vasculature (1). FGF-2 and VEGF-A have been regarded as likely candidates for inducers of angiogenesis. VEGF-A is a positive regulator of tumor-associated angiogenesis, and it stimulates endothelial cell proliferation and enhances vascular permeability. Many reports have shown that VEGF-A is closely related to growth and prognosis in oral cancers (2-5). FGF-2 is the prototypic member of a family containing at least 23 structurally-related polypeptide growth factors (6). It is expressed ubiquitously in cells of mesoderm and neuroectodermal origin, and in a variety of tumor cells. In vitro, FGF-2 is a potent mitogen for different cell types, including vascular endothelial cells, fibroblasts and cancer cells such as squamous cell carcinoma (7) and salivary adenocarcinoma $(8,9)$. In vivo, FGF-2 is a potent inducer of angiogenesis and has pleiotropic effects both on development, differentiation in various organs, and tumorigenesis $(10,11)$.

FGF-2 is secreted despite lacking a leader sequence, which targets intracellular proteins for secretion to the extracellular environment, and externalized FGF-2 needs to be released and solubilized from the extracellular matrix. We initially isolated heparin-binding protein of $17 \mathrm{kDa}$ in 1991 from the medium conditioned by human epidermoid carcinoma A431 cells and designated the protein as heparin-binding protein 17 (HBp17) (12). HBp17 was found to bind FGF-1 and FGF-2 in a non-covalent and reversible manner $(12,13)$. Owing to its capacity to bind FGFs, HBp17 was re-named fibroblast growth factor-binding protein-1 (FGFBP-1) (14). Binding of HBp17/FGFBP-1 to FGF-2 mediates the release of immobilized FGF-2 from the extracellular matrix allowing it to reach its receptor, suggesting that HBp17/FGFBP-1 serves as an extracellular switch molecule for FGF-2 (12-17). Recently, it was reported that HBp17/FGFBP-1 also interacted with FGF-7, -10, and -22, and regulates FGF activities (18). Upregulation of HBp17/FGFBP-1 was found in various tumors, including head and neck, skin and colon cancers (19-21). In 
Table I. Patient characteristics.

\begin{tabular}{lccrr}
\hline \multirow{2}{*}{$\begin{array}{c}\text { Histopathological } \\
\text { grade }\end{array}$} & $\begin{array}{c}\text { Number } \\
\text { of cases }\end{array}$ & $\begin{array}{c}\text { Average age } \\
\text { (years) }\end{array}$ & \multicolumn{2}{c}{ Gender } \\
\cline { 4 - 5 } & Male & Female \\
\hline Normal gingiva & 10 & 24.3 & 3 & 7 \\
Hyperplasia & 20 & 58.7 & 10 & 10 \\
Moderate dysplasia & 20 & 65.8 & 12 & 8 \\
Severe dysplasia & 14 & 61.7 & 8 & 6 \\
OSCC & 30 & 64.2 & 20 & 10 \\
\hline
\end{tabular}

addition, the growth and angiogenesis of xenografted tumors in mice was decreased in parallel with a reduction in $\mathrm{HBp} 17 /$ FGFBP-1 expression, suggesting that human tumors utilize HBp17/FGFBP-1 as an angiogenic switch molecule (22).

Although angiogenesis has been shown to be an independent prognostic indicator in a number of cancers, little is known about its significance in premalignant lesions in the head and neck region. To our knowledge there have been no reports on the role of HBp17/FGFBP-1 in premalignant lesions. The aim of this study was to investigate the expr-ession of $\mathrm{HBp} 17 /$ FGFBP-1, FGF-2 and VEGF-A in the multistep process of head and neck tumorigenesis, and to evaluate the relationships between the expression of these angiogenic factors and tumor microvessel densities, TNM stages, OSCC recurrence interval and clinicopathological stages.

\section{Materials and methods}

Selection of specimens. Paraffin-embedded specimens representing premalignant lesions and oral squamous cell carcinoma (OSCC) were prepared in the Center for Oral Clinical Examination, Hiroshima University Hospital after surgical excision in the Department of Molecular Oral Medicine and Maxillofacial Surgery at Hiroshima University Dental Hospital. Tissue samples of normal oral epithelium were obtained from surgical specimens of non-cancer patients. The Ethics Committee in Hiroshima University approved specimen collection. All tissue samples were fixed in $10 \%$ neutral formalin for $24 \mathrm{~h}$. Sections were prepared at $4 \mu \mathrm{m}$ in thickness for immunohistochemical procedures.

Antibodies. A monoclonal anti-HBp17 antibody designated as C9 (10) was used in this study. C9 hybridoma cells were cultured in RD medium [RPMI-1640 medium: Dulbecco's modified Eagle's medium (DMEM); 1:1] supplemented with $10 \mu \mathrm{g} / \mathrm{ml}$ insulin, $5 \mu \mathrm{g} / \mathrm{ml}$ transferrin, $10 \mu$ 2-mercaptoethanol, $10 \mu \mathrm{M} 2$-aminoethanol and $10 \mathrm{nM}$ selenite (RD+5F). After being filtered with a $0.45-\mu \mathrm{m}$ filter (Millipore), the conditioned medium was passed through Protein $\mathrm{G}$ affinity chromatography (Amersham Bioscience, Buckinghamshire, UK), and HBp17 antibody $\mathrm{C} 9$ was eluted by $0.1 \mathrm{M}$ glycine- $\mathrm{HCl}(\mathrm{pH} 2.7)$. After being purified, $10 \mu \mathrm{g} / \mathrm{ml}$ of the $\mathrm{C} 9$ antibody was used for immunostaining.

Monoclonal anti-FGF-2 antibody (clone bFM-1, diluted 1:100; final concentration, $2 \mu \mathrm{g} / \mathrm{ml}$ ) was purchased from Upstate Biotechnology Inc. (Lake Placid, NY). Monoclonal anti-VEGF-A antibody (clone R-11, diluted 1:100; final concentration, $2 \mu \mathrm{g} / \mathrm{ml}$ ) was from IBL (Int. Gunma, Japan). Monoclonal anti-von Willebrand factor antibody (vWF, diluted 1:40; final concentration, $5.75 \mu \mathrm{g} / \mathrm{ml}$ ) was purchased from Dako (A/S, Denmark).

Immunohistochemistry. The expression of HBp17/FGFBP-1, FGF-2, VEGF-A and vWF were analyzed with a three-stage avidin-biotin immunoperoxidase technique using a vectastain mouse ABC kit (Vector Laboratories, Burlingame, CA, USA). Briefly, deparaffinized tissue sections were incubated with $1 \% \mathrm{H}_{2} \mathrm{O}_{2}$ in methanol for $30 \mathrm{~min}$ at room temperature to block endogenous peroxidase activity, followed by incubation with $1.5 \%$ normal horse serum at $37^{\circ} \mathrm{C}$ for $30 \mathrm{~min}$ to prevent non-specific binding. Incubation with primary antibody was performed at $37^{\circ} \mathrm{C}$ for $60 \mathrm{~min}$ using predetermined optimal dilution. As negative controls, sections were probed with $1.5 \%$ normal horse serum. Sections were then incubated with biotinylated anti-mouse immunoglobulin for $60 \mathrm{~min}$, followed by 30-min incubation with Avidin-Biotin-peroxidase-Complex at room temperature. Reaction products were visualized by immersing sections in $10 \mathrm{mM}$ Tris- $\mathrm{HCl}$ (pH.7.4) containing $1 \mathrm{mg} / \mathrm{ml} \mathrm{3,3}$ diaminobenzidine (DAB) and $0.03 \%$ hydrogen peroxide. The sections were counterstained with Mayer's solution.

Expression score. A semi-quantitative method was used to evaluate the degree of immunostaining ranging from - (no expression $),+$ (weak), ++ (moderate), to +++ (highest level of expression) on a cell-by-cell basis in 5 microscopic fields (x33 magnification). For each section, the percentage of cells stained at x33 magnification for five different fields were multiplied by that intensity value and the five products determined were added together to obtain a weighed average staining score.

Microvessel density (MVD). The microvessels were highlighted by staining endothelial cells with anti-vWF antibody by immunohistochemistry. MVD were counted at x200 magnification for ten fields and the mean value of those ten fields in each sample was calculated.

Statistical analysis. Data are presented as mean \pm SD. The relationship between FGF2, HBp17/FGFBP-1, VEGF-A expression and MVD in cancer and premalignant lesions was determined with the Spearman correlation test. The KruskalWallis test was used when comparing immunohistological expression in the TNM stages of oral squamous cell carcinoma groups. All tests were three-tailed, and $\mathrm{P} \leq 0.05$ was considered to indicate statistical significance.

\section{Results}

Thirty specimens of OSCC, 54 specimens of premalignant oral lesions including 20 hyperplasias, 20 moderate dysplasias, 14 severe dysplasias and 10 control specimens were studied. There were 53 male and 41 female subjects, and the average age of the patients was 54.9 years old (Table I).

HBp 17/FGFBP-1 expression. Fifty percent of normal gingiva showed weak expression at the cytoplasm of the spinous layer 


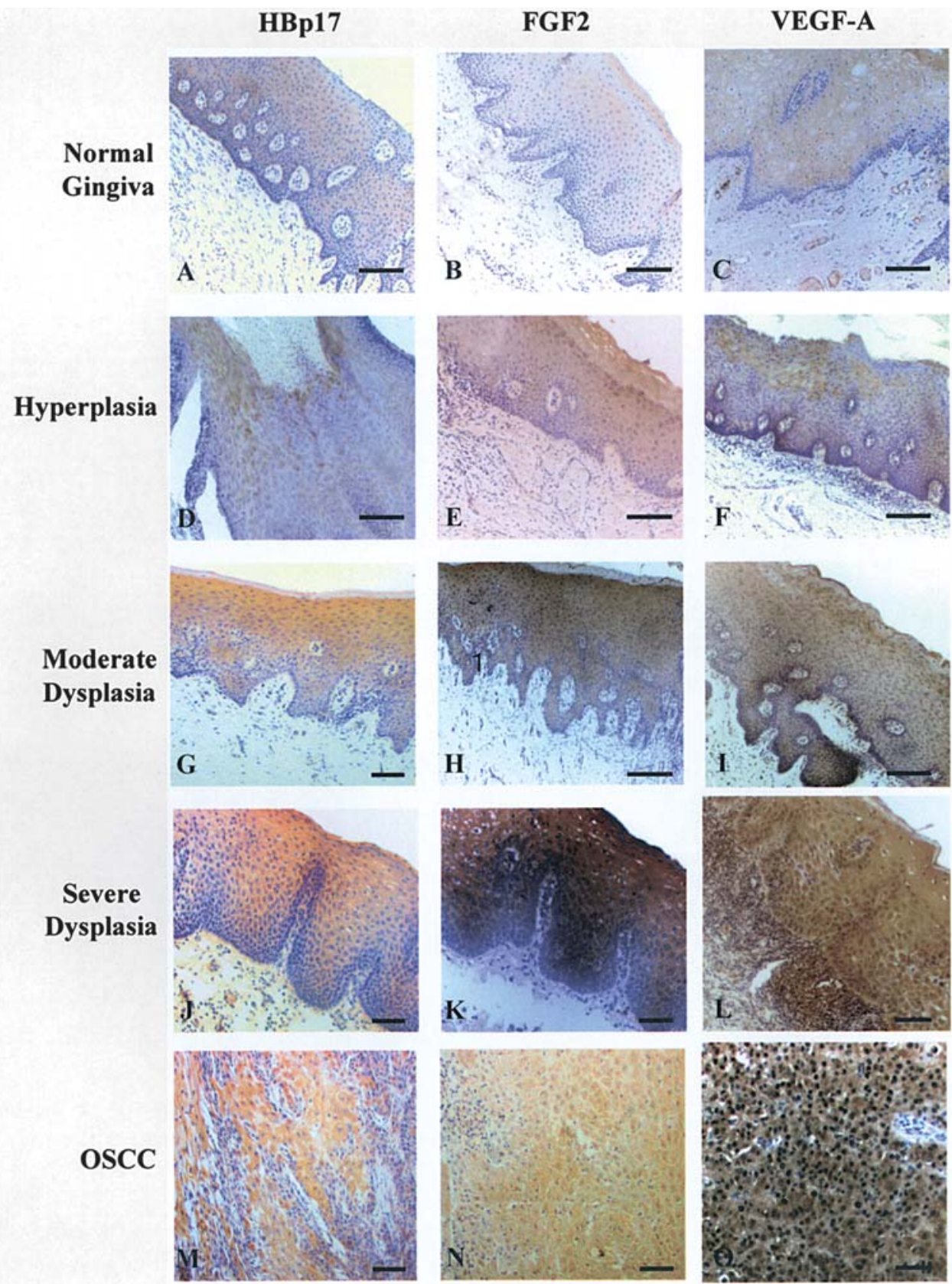

Figure 1. Immunohistochemical expression of HBp17/FGFBP-1, FGF-2 and VEGF-A in normal gingivas, hyperplasias, moderate dysplasias, severe dysplasias and oral squamous cell carcinomas. Normal gingiva showed weak expression of HBp17/FGFBP-1, FGF-2 and VEGF-A in the cytoplasm of spinous layer cells (Fig. 1A, B and C). Hyperplasias showed limited expression of HBp17/FGFBP-1, FGF-2 and VEGF-A in the acanthotic epithelium (Fig. 1D, $\mathrm{E}$ and F). Moderate dysplasias, severe dysplasias and OSCC strongly expressed HBp17/FGFBP-1 and FGF-2 in the cytoplasm of cells (Fig. 1G, H, J, K, M and N). VEGF-A expression was detected not only in the cytoplasm but also in cell nuclei in moderate dysplasia, severe dysplasia and OSCC tumors (Fig. 1I, $\mathrm{L}$ and $\mathrm{O})$. Scale bar, $50 \mu \mathrm{m}$.

Table II. Immunostaining intensities for HBp17/FGFBP-1, FGF-2 and VEGF-A in normal gingivas, hyperplasias, moderate dysplasias, severe dysplasias and oral squamous cell carcinomas.

\begin{tabular}{|c|c|c|c|c|c|c|c|c|c|c|c|c|c|c|c|}
\hline \multirow[b]{2}{*}{ Cases } & \multicolumn{5}{|c|}{ HBpl7 } & \multicolumn{5}{|c|}{ FGF-2 } & \multicolumn{5}{|c|}{ VEGFA } \\
\hline & - & + & ++ & +++ & (\% positive) & - & + & ++ & +++ & (\% positive) & - & + & ++ & +++ & ( $\%$ positive) \\
\hline Normal gingiva & 5 & 5 & 0 & 0 & $(50)$ & 6 & 4 & 0 & 0 & $(40)$ & 5 & 5 & 0 & 0 & $(50)$ \\
\hline Hyperplasia & 8 & 6 & 6 & 0 & $(60)$ & 12 & 6 & 2 & 0 & $(40)$ & 10 & 10 & 0 & 0 & $(50)$ \\
\hline Moderate dysplasia & 6 & 8 & 6 & 0 & (70) & 10 & 4 & 4 & 2 & $(50)$ & 8 & 4 & 6 & 2 & (60) \\
\hline Severe dysplasia & 0 & 0 & 4 & 10 & $(100)$ & 0 & 0 & 8 & 6 & $(100)$ & 2 & 2 & 4 & 6 & (85.7) \\
\hline OSCC & 0 & 0 & 22 & 8 & (100) & 0 & 2 & 22 & 6 & (100) & 6 & 2 & 14 & 8 & (80) \\
\hline
\end{tabular}




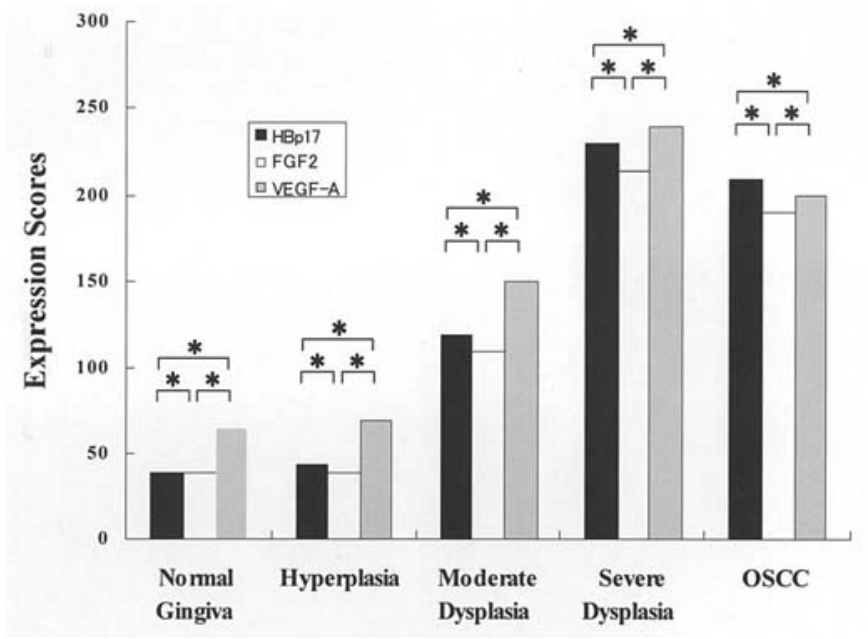

Figure 2. Staining scores for HBp17/FGFBP-1, FGF-2 and VEGF-A in multisteps of oral tumorigenesis. Staining scores gradually increased as gingival lesions proceeded from normal to hyperplasia, moderate dysplasia, severe dysplasia and OSCC. Staining scores were highest in severe dysplasia. At all stages of oral tumorigenesis, staining scores of HBp17/ FGFBP-1 and FGF-2 showed significant correlations.

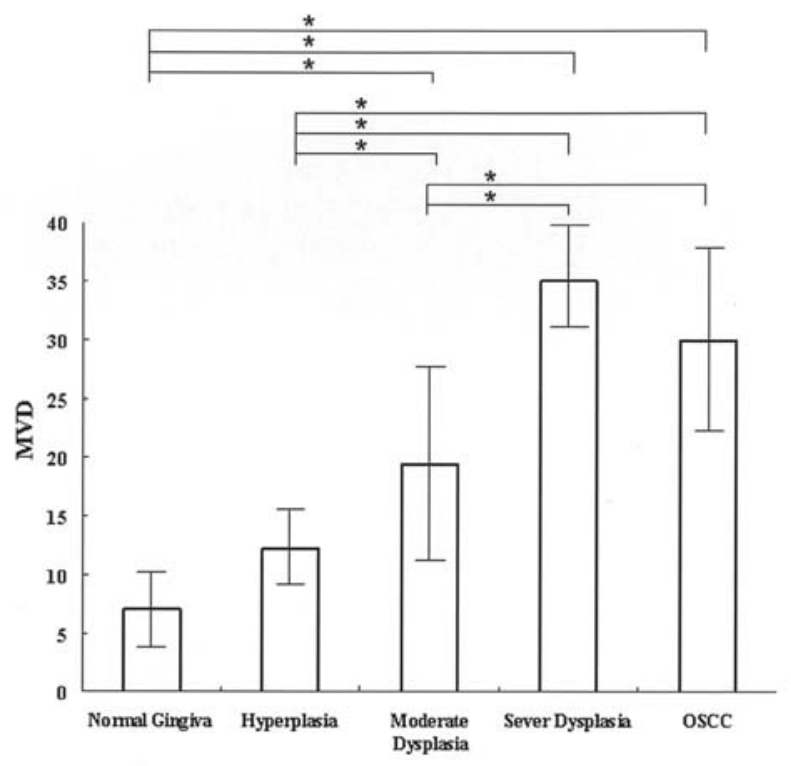

Figure 3. Microvessel density (MVD) in multisteps of oral tumorigenesis. MVD increased gradually with the severity of epithelial dysplasia, ${ }^{*} \mathrm{p}<0.05$.

(Fig. 1A). Sixty percent of hyperplasias showed limited expression at the acanthotic epithelium (Fig. 1D). Seventy percent of moderate dysplasias and $100 \%$ of severe dysplasias and OSCC strongly expressed HBp17/FGFBP-1 in the cytoplasm (Fig. 1G, J, M and Table II).

FGF-2 expression. Forty percent of normal tissue expressed FGF-2 in the cytoplasm in the spinous layer (Fig. 1B) and hyperplasias expressed FGF-2 in the cytoplasm in the acanthotic epithelium (Fig. 1E). The staining intensity was greater in the upper layers of moderate dysplasias (Fig. 1H), and FGF-2 staining significantly increased in intensity through to the severe dysplasia (Fig. 1K). In OSCC, FGF-2 expression was detected in the cytoplasm of tumor cells (Fig. 1N). These
Table III. Relationships between MVD and expression of HBp17/FGFBP-1, FGF-2 and VEGF-A at all stages of tumorigenesis. ${ }^{\mathrm{a}}$

\begin{tabular}{|c|c|c|c|}
\hline & $\begin{array}{l}\text { Expression } \\
\text { score }\end{array}$ & $\begin{array}{c}\text { MVD } \\
(\text { mean } \pm S D)\end{array}$ & P-value \\
\hline \multicolumn{4}{|c|}{ Hyperplasia } \\
\hline HBpl7 & 45 & & \\
\hline FGF-2 & 40 & $12.2 \pm 3.56$ & $*$ \\
\hline VEGF-A & 70 & & \\
\hline \multicolumn{4}{|c|}{ Moderate dysplasia } \\
\hline HBpl7 & 120 & & \\
\hline FGF-2 & 110 & $19.4 \pm 8.9$ & $*$ \\
\hline VEGF-A & 150 & & \\
\hline \multicolumn{4}{|c|}{ Severe dysplasia } \\
\hline HBpl7 & 230 & & \\
\hline FGF-2 & 215 & $35.1 \pm 4.8$ & $*$ \\
\hline VEGF-A & 240 & & \\
\hline \multicolumn{4}{|l|}{ OSCC } \\
\hline HBpl7 & 210 & & \\
\hline FGF-2 & 190 & $30.1 \pm 7.3$ & $*$ \\
\hline VEGF-A & 200 & & \\
\hline
\end{tabular}

${ }^{\mathrm{a}}$ Expression scores are mean values, ${ }^{*} \mathrm{p}<0.05$.

data suggested that FGF-2 co-localized with HBp17/FGFBP-1 in both normal and tumor tissues.

VEGF-A expression. The immunohistochemical staining of VEGF-A appeared to be localized to the cytoplasm of normal control cells, hyperplasias, and endothelial cells lining microvessels (Fig. 1C and F). In the case of dysplasias of different degrees, the level and extent of VEGF-A expression increased with the severity of epithelial dysplasia. VEGF-A expression was detected not only in the cytoplasm but also in the nuclei of tumor cells (Fig. 1I, L and O). As the grade of dysplasia increased, the extent and levels of expression of HBp17/ FGFBP-1, FGF2 and VEGF-A also increased. The expression of HBp17/FGFBP-1, FGF-2 and VEGF-A showed significant correlations $(\mathrm{P}<0.05)$ at all stages (Fig. 2).

Microvessel density (MVD) measured by vWF expression gradually increased with the severity of epithelial dysplasia. MVD was $7.02 \pm 3.04$ in normal gingival, 12.2 \pm 3.56 in hyperplasias, $19.4 \pm 8.9$ in moderate dysplasias, $35.1 \pm 4.8$ in severe dysplasias, and 30.1 \pm 7.3 in OSCC. MVD was the highest in severe dysplasias (Fig. 3). The expression of HBp17/FGFBP-1, FGF-2 and VEGF-A showed significant correlation with MVD at all steps of tumorigenesis (Table III). In contrast, no associations were found between expression score and TNM stages or recurrence interval (data not shown).

\section{Discussion}

We have previously reported that limited expression of FGF-1 and FGF-2 was detected in the spinous layer of normal gingiva, 
and stronger expression was detected in the cytoplasm of oral squamous cell carcinomas by immunohistochemistry (7). A second study also suggested that HBp17/FGFBP-1 mRNA was detected not only in tumor cells but also in keratinocytes of normal mucosa (23). The results of the present study agree with the earlier findings in demonstrating that co-localization of FGF-2 and HBp17/FGFBP-1 was observed in the spinous layer of normal gingiva. The extent and intensity of expression of these two markers increased with the severity of epithelial dysplasia. Therefore, we propose that HBp17/FGFBP-1 in collaboration with FGF-2 has a regulatory role in tumorigenesis and normal development in epithelial tissue.

In a variety of cancers angiogenic factors have become significant prognostic markers (24-28). Our study showed that the expression of the angiogenic molecules HBp17/ FGFBP-1, FGF-2 and VEGF-A also increased with the severity of epithelial dysplasia, and the expression score was highly correlated at all stages of the multistep development of head and neck cancer. The expression score was highest in severe dysplasia, but not in OSCC. This difference may be due to accumulated genetic alterations within tumor cells leading to growth factor independence. Andreas et al also reported an increase in HBp17/FGFBP-1 expression during development and tumorigenesis and a relative decrease in HBp17/FGFBP-1 expression in later stages of carcinogenesis (29).

For evaluating angiogenesis during neoplastic development, we measured MVD and used it to represent the angiogenic status of lesions. We found a significant association between MVD and expression of HBp17/FGFBP-1, FGF-2, and VEGF-A. These data are supported by a study of head and neck cancer in which $\mathrm{Li}$ et al reported a significant association between increased expression of VEGF or FGF-2 and MVD in different histological stages of head and neck tumorigenesis (30). Frank et al reported that enhanced expression of FGF-2 and FGF-2 receptors by cancer cells and vascular endothelial cells promoted cancer growth and metastasis through angiogenesis (31). Subsequently, Fukuiwa et al found a significant correlation between VEGF expression and MVD (32).

Our results showed no association between angiogenic factor expression and recurrence intervals or TNM stages (data not shown). Another study found that the elevated level of both IL- 8 and VEGF correlated with an increased incidence of recurrence, shorter disease-free intervals and higher initial TNM stage in head and neck tumorigenesis (33). However, Petri et al found no association with VEGF expression and TNM stages or MVD (34). Similarly, Burian et al observed no association between FGF-2 expression and TNM stages or MVD (35). In the present study, a significant increase in MVD observed in severe dysplasia rather than in moderate dysplasia and in OSCC. The decrease in MVD in tumors compared to severe dysplasia may be due to a decreased requirement for further angiogenesis once a certain stage in the disease process has been reached. This idea is supported by Li et al who also found increased expression of MVD in severe dysplasia compared to tumor specimens (30).

In conclusion, our results suggest that the angiogenic factors HBp17/FGFBP-1, FGF-2 and VEGF-A may together provide essential regulatory signals for the induction of tumor angiogenesis. The strongest expression of angiogenic factors and highest MVD in the severe dysplasia stage suggest potential targets for therapeutic strategies. Thus, the appropriate choice of therapy before or at the stage of severe dysplasia might prevent further malignant progression by controlling angiogenesis.

\section{Acknowledgments}

We thank Dr Y. Ogawa of the Center for Oral Clinical Examination, Hiroshima University Hospital for her helpful assistance. This study was partially supported by the Grantin-Aid for B (2) 17390539 from the Ministry of Education, Science, Sports and Culture, and by a grant from the Smoking Research Foundation to TO. JDS was supported by grant P20-RR016463 from the National Institutes of Health.

\section{References}

1. Hanahan D and Folkman J: Patterns and emerging mechanisms of the angiogenic switch during tumorigenesis. Cell 86: 353-364, 1996.

2. Denhart BC, Guidi AJ, Tognazzi HF and Brown LF: Vascular permeability factor/vascular endothelial growth factor and its receptors in oral and laryngeal squamous cell carcinoma and dysplasia. Lab Invest 77: 659-664, 1997.

3. Ninck S, Reisser C, Dyckhoff G, Helmke B, Bauer H and Herold MC: Expression profiles of angiogenic growth factors in squamous cell carcinomas of the head and neck. Int J Cancer 106: 34-44, 2003.

4. Sauter ER, Nesbit M, Watson JC, Klein SA, Litwin SL and Herlyn M: Vascular endothelial growth factor is a marker of tumor invasion and metastasis in squamous cell carcinomas of the head and neck. Clin Cancer Res 75: 775-782, 1999.

5. Smith BD, Smith GL, Carter D, Sasaki CT and Haffty BG: Prognostic significance of vascular endothelial growth factor protein levels in oral and oropharyngeal squamous cell carcinoma. J Clin Oncol 18: 2046-2052, 2000.

6. Bikfalvi A, Klein S, Pintucci G and Rifkin DB: Biological roles of fibroblast growth factor-2. Endocr Rev 18: 26-45, 1997.

7. Myoken Y, Myoken Y, Okamoto T, Sato JD and Takada K: Immunocytochemical localization of Fibroblast growth factor1 (FGF-1) and FGF-2 in oral squamous cell carcinoma (SCC). J Oral Pathol Med 23: 451-456, 1994.

8. Myoken Y, Myoken Y, Okamoto T, Kan M, McKeehan WL, Sato JD and Takada K: Expression of fibroblast growth factor-1 (FGF-1), FGF-2 and FGF receptor-1 in a human salivary-gland adenocarcinma cell line: evidence of autocrine growth. Int $\mathrm{J}$ Cancer 65: 650-657, 1996.

9. Zhang Y, Wang H, Toratani S, Sato JD, Kan M, McKeehan WL and Okamoto T: Growth inhibition by keratinocyte growth factor receptor of human salivary adenocarcinoma cells through induction of differentiation and apoptosis. Proc Natl Acad Sci USA 98: 11336-11340, 2001

10. Basilico C and Moscatelli D: The FGF family of growth factors and oncogenes. Adv Cancer Res 59: 115-165, 1992.

11. Eswarakumar VP, Lax L and Schlessinger J: Cellular signaling by fibroblast growth factor receptors. Cytokine Growth Factor Rev 16: 139-149, 2005

12. Wu D, Kan M, Sato GH, Okamoto T and Sato JD: Characterization and molecular cloning of a putative binding protein for heparin-binding growth factors. J Biol Chem 266: 16778-16785, 1991.

13. Liu X, Shi S, Chen JH, Wu D, Kan M, Myoken Y, Okamoto T and Sato JD: Human fibroblast growth factor-binding protein HBp 17 enhances the tumorigenic potential of immortalized squamous epithelial cells. In: Animal Cell Technology: Basic and Applied Aspects. Vol. 12. Kluwer Academic Publishers, Dordrecht, pp343-352, 2002.

14. Czubayko F, Smith RV, Chung HC and Wellstein A: Tumor growth and angiogenesis induced by a secreted binding protein for fibroblast growth factors. J Biol Chem 269: 28243-28248, 1994.

15. Abuharbeid S, Czubayko F and Aigner A: The fibroblast growth factor-binding protein FGF-BP. Int J Biochem Cell Biol 38: 1463-1468, 2006. 
16. Aigner A, Butscheid M, Kunkel P, Krause E, Lamszus K, Wellstein A and Czubayko F: An FGF-binding protein (FGF$\mathrm{BP})$ exerts its biological function by parallel paracrine stimulation of tumor cell and endothelial cell proliferation through FGF-2 release. Int J Cancer 92: 510-517, 2001.

17. Mongiat M, Otto J, Oldershaw R, Ferrer F, Sato JD and Iozzo RV: Fibroblast growth factor-binding protein is a novel partner for perlecan protein core. J Biol Chem 276: 10263-10271, 2001.

18. Beer HD, Bittner M, Niklaus G, Munding C, Max N and Goppelt A: The fibroblast growth factor binding protein is a novel interaction partner of FGF-7, FGF-10 and FGF-22 and regulates FGF activity: implications for epithelial repair. Oncogene 24: 5269-5277, 2005.

19. Ray R, Cabal MR, Moser AR, Waldman T, Zipper LM, Aigner A, Byers SW, Riegel AT and Wellstein A: Upregulation of fibroblast growth factor-binding protein, by beta-catenin during colon carcinogenesis. Cancer Res 63: 8085-8089, 2003.

20. Tassi E, Al-Attar A, Aigner A, Swift MR, McDonnell K, Karavanov A and Wellstein A: Enhancement of fibroblast growth factor (FGF) activity by an FGF-binding protein. J Biol Chem 276: 40247-40253, 2001.

21. Sauter ER, Nesbit M, Tichansky D, Liu ZJ, Shirakawa T, Palazzo J and Herlyn M: Fibroblast growth factor-binding protein expression changes with disease progression in clinical and experimental human squamous epithelium. Int $\mathbf{J}$ Cancer 92: 374-381, 2001.

22. Czubayko F, Liaudet-Coopman ED, Aigner A, Tuveson AT, Berchem GJ and Wellstein A: A secreted FGF-binding protein can serve as the angiogenic switch in human cancer. Nat Med 3: 1137-1140, 1997.

23. Okamoto T, Tanaka Y, Kan M, Sakamoto A, Takada K and Sato JD: Expression of fibroblast growth factor binding protein HBp17 in normal and tumor cells. In Vitro Cell Dev Biol Anim 32: 69-71, 1996.

24. Inone K, Ozeki Y, Suganuma T and Tanaka S: Vascular endothelial growth factor expression in primary esophageal squamous carcinoma. Cancer 79: 206-213, 1997.

25. Singh SK, Weyler J, Menuella J, Martin H, Peter B and Marck EV: Angiogenic cytokines in mesothelioma: a study of VEGF, FGF-1 and FGF-2, and TGFß expression. J Pathol 189: 72-78, 1999.
26. Pamela JP, Katherine A, Staskus KG, Mohanraz D, Twiggs LB, Carson LF and Ramakrishnan S: Vascular endothelial growth factor expression in early stage ovarian carcinoma. Cancer 80: 98-105, 1997.

27. David Z, Douglas CM, Sato Y, Rafkin DB and Burstein DE: Immunohistochemical localization of basic fibroblast growth factor in astrocytomas. Cancer Res 50: 7393-7398, 1990.

28. Calomer R, Apricio J, Montero S, Guzman C, Larrodera L and Funes HC: Low level of basic fibroblast growth factor (bFGF) are associated with a poor prognosis in human breast carcinoma. Br J Cancer 76: 1215-1220, 1997.

29. Andreas K, Wang HL, Darwiche N, Harris V and Wellstein A: Expression of a binding protein for FGF is associated with epithelial development and skin carcinogenesis. Oncogene 14: 2671-2681, 1997.

30. Li C, Shintani S, Terakado N, Klosek SK, Ishikawa T, Nakashiro $\mathrm{K}$ and Hamakawa $\mathrm{H}$ : Microvessel density and expression of vascular endothelial growth factor, basic fibroblast growth factor, and platelet-derived endothelial growth factor in oral squamous cell carcinomas. Int J Oral Maxillofac Surg 34: $559-565,2005$.

31. Frank RD, Jeffrey S, Roselle E and Donald K: Expression of basic fibroblast growth factor and its receptors by head and neck squamous carcinoma tumor and vascular endothelial cells. Am J Surg 174: 540-544, 1997.

32. Fukuiwa T, Takebayashi Y, Akiba S, Matsuzaki T, Hanamure Y, Miyadera K, Yamada Y and Akiyama S: Expression of thymidine phosphorylase and vascular endothelial cell growth factor in human head and neck squamous cell carcinoma and their different characteristics. Cancer 55: 960-969, 1999.

33. Rosselle JE, Jeffery DS and Donald LK: Role of angiogenic factors: coexpression of interleukin-8 and vascular endothelial growth factors in patients with head and neck squamous carcinoma. Laryngoscope 109: 687-693, 1999.

34. Petri S, Heikkila P, Anttonen A, Kajanti M and Joensuu H: Vascular endothelial growth factor in squamous cell head and neck carcinoma: expression and prognostic significance. Mod Pathol 10: 1128-1133, 1997.

35. Burian M, Quint $\mathrm{CH}$ and Neuchrist C: Angiogenic factors in laryngeal carcinomas: do they have prognostic relevance? Acta Otolaryngol 119: 289-292, 1999. 